Original Research Paper

\title{
Willingness to Communicate in English among Trainee Teachers in a Malaysian Private University
}

\author{
Ahmed Fahim and Mogana Dhamotharan \\ Faculty of Education, SEGi University, Selangor, Malaysia
}

Article history

Received: 23-04-2016

Revised: 29-05-2016

Accepted: 31-05-2016

Corresponding Author:

Ahmed Fahim

Faculty of Education, SEGi

University, Selangor, Malaysia

Email: afy0123@gmail.com

\begin{abstract}
Willingness to Communicate (WTC) in English has become a field of interest since the construct was introduced by McCroskey and Baer in 1985. This study, investigated 230 trainee teachers' Willingness to Communicate in English in terms of gender, nationality, ethnic group, course and years of study at the Faculty of Education in a Malaysian private university. The results of the study revealed that participants had moderate willingness to communicate in English and preferred to initiate communication in English with friends rather than acquaintances or strangers. There were significant differences among participants in WTC based on their gender, ethnic group, type of study and the period they spent in the Faculty of Education. Changing classroom environment, grouping technique and providing opportunities outside the classroom for communicating in English through English language clubs, journeys to native speaking countries, debates, drama, songs and free writing competitions can help them communicate in English away from the stress caused by curriculum based activities linked to credits and grades.
\end{abstract}

Keywords: Willingness to Communicate in English, Trainee Teachers, Ethnic Groups

\section{Introduction}

In spite of the high expectations stated in Malaysia Educational Blueprint (2013-2025), 64\% of Malaysian tertiary education candidates were categorized as limited or very limited users of English in the Malaysian University English Test (MUET) which gives a complete reason for $48 \%$ of the of employers to reject those with poor English (MGBSLN, 2015), from (http://www.nst.com.my/news). Teachers lack variety of professional development fundamentals, struggle with inadequate linguistic knowledge and poor pedagogical skills (Fern and Jiar, 2012). Challenges facing both teachers and learners were figured out as a result of constant fluctuation in the policy related to English language in Malaysia (Ida Fatimawati, 2012). Studies on students who were exposed to English for 11 years in primary and secondary schools, showed that they still have difficulties related to language proficiency (Ida Fatimawati, 2012) and their written communication was described to be under satisfactory level (Mahady, n.d.). Limited opportunities to use English outside the classroom widened the proficiency gap between students joining tertiary education from urban and rural areas where English is regarded as a foreign language (Gill, 2005). Not apart from that trainee teachers' Willingness to Communicate (WTC) in English is not given the due concern and the factors affecting their low communication capacity in English was not investigated in details within the Malaysian context.

Under the British rule, English was the medium of education for most of private schools. Well-educated people were greatly affected by the British education system and by their western lifestyle, which widened the gaps between social classes and in some cases led to forms of tension (Ida Fatimawati, 2012). To achieve the true freedom, policy makers after independence constitutionally stated Bahasa Melayu as the official language of Malaysia. National unity was the most critical goal of the new rulers of Malaysia after independence. Thus, in 1957 all existing schools were converted to National or National-Type schools and the national language, BahasaMelayu (Malay language), was made a compulsory subject for all schools, but English remained as one of the essential languages used in the country. Malay medium primary schools renamed to be 
national schools while English, Chinese and Tamil schools became national-type schools. Economy was also an accelerator of national unity by applying the new socio-economic policy during the 70 and $80 \mathrm{~s}$ of the twentieth century. Integration of all the components of the society in the growing economy was one of the targets of the educational system (Ida Fatimawati, 2012). Unaffected by this fluctuation in the educational policy, English remained the medium of instruction in many higher education institutions. Collaboration between local and international universities was another facility to provide large-scale opportunities for students. University College Act 1996 gave universities more freedom to run their institutions. Inspired by Malaysia Educational Blueprint (2013-2025) (Blueprint, 2013), Institutions of Higher Education "play an important role in training the people necessary for the academic as well as the manpower needs of the nation" (LOM, 2006, p.11). The quality of English language used by university students attracted many researches in the Malaysian context. (Yousef et al., 2013) were interested in studying the Malaysian Pre-Service English Teachers' Willingness to Communicate (WTC) in English with a focus on oral communication. They tried to find out about real solutions to motivate oral communication among learners of English as a Second Language (ESL).

By shedding light on this phenomenon, a better understanding of the factors affecting trainee teachers' Willingness to Communicate in English could be achieved. The findings of this study are expected to help policy makers to find some answers to the currently debatable problem of English language efficiency facing both teachers as well as students at schools and universities. Understanding the effects of gender, nationality, ethnicity, type of study, the period spent in tertiary education on the Willingness to Communicate is important to help lecturers and curriculum designers to improve communication in English. Researchers in the field of tertiary education may build on this study and use the findings to bridge the knowledge gap in the literature.

\section{Literature Review}

\section{Willingness to Communicate (WTC)}

The concept Willingness to Communicate (WTC) was first introduced by (McCroskey and Baer, 1985, p.8) to be "the individuals' tendency to initiate communication when they are free to do so". The present Willingness to Communicate (WTC) was initiated after earlier works on Unwillingness to Communicate by (Burgoon, 1976), predispositions towards verbal behavior (Mortensen et al., 1977) and work on shyness by (Crozier, 1982). Communication Motivation (CM) was discussed by McCroskey (2006), stating that individuals have many reasons that stimulate them to communicate; (i) individuals seek affinity (liking, being attracted to or wanting to be near some other person); (ii) acquiring information or understanding; (iii) influencing others, reaching decisions; (iv) confirming beliefs and (v) expressing feelings. McCroskey (2006) also investigated the reasons that made an individual decide to initiate communication with a particular person. An interesting study carried out by (Priest and Sawyer, 1967) concluded that proximity plays a great role in choosing pairs among 25,000 university students. The same was noticed among school children, who normally choose to talk to their classmates next to them simply because they are next to them. Attraction (physical, social and task) is found to form individuals' decision to communicate with noticeable focus on the physical attraction. Homophily, utility (ability to help) and loneliness are all factors that affect people's choice to communicate with a particular.

\section{Willingness to Communicate (WTC) in Second language context}

Cao (2011) involved twelve participants from China and Korea and one student from Europe who attended an intact advanced-level English for Academic Purposes class for five months. The participants' stay in New Zealand ranged from one month to over a year. They were exposed to English for seven years in the home country. The researcher collected data through classroom observations, stimulated-recall interviews and reflective journals. To ensure the validity of the data, the researcher triangulated the data sources to compare the participants' WTC in class, in stimulated-recall interviews and in journal entries in addition to the researcher's field notes. WTC scores at three different points within the five months revealed an overall change in WTC for the class as well as for individuals with a noticeable fluctuation in WTC levels for four students over time. The results of situational WTC in class also showed statistically significant differences between over the five- month time span. The changes in learners over time were found to be due to the variations in the underlying factors of WTC. The longitudinal study claimed that the dynamic fluctuations in situational WTC were due to the joint effects of classroom context, individual and linguistic variables. Although the researcher noted limitations that were due to the small sample size and lack of generalizability of the findings, he advised teachers to maximize the time devoted for motivating topics, challenging but manageable activities, switching between group and paired activities and providing sufficient supportive teacher behaviour. Future research was recommended to investigate the relationship between the factors affecting not only the learners' Willingness to Communicate but also the quality of their 
communication and the potential this participation has for language development need to be investigated.

(Lahuerta, 2014) investigated Willingness to Communicate among 195 students majoring in Arts, Finance, Tourism, Computing and Industrial Engineering at the University of Oviedo. English for Specific Purposes is one of the subjects in their curriculum and their mother tongue is Spanish. None of the subjects provided exposure to English except the English for Specific Purposes course. An English language test with a total of 200 items including listening comprehension, grammar and use of English items was conducted. Seven questionnaires were used to explore Willingness to Communicate in English, Communication Anxiety in English, Self-perceived Communication Competence in English, Motivation using Attitude/Motivation Test Battery, Motivational intensity, Attitudes towards Learning English and Desire to Learn English. Lahuerta ran regression analyses to find out the relation between the six mentioned independent variables and Willingness to Communicate in English. The results showed a significant statistical relationship between Willingness to Communicate and the three elements used to measure motivation. Attitude to learning English was found to be able to predict $15.3 \%$ of the participants' Willingness to Communicate with friends and acquaintances, Motivational Intensity predicted 10.9\% and Desire to learn English predicted $12.6 \%$ with a significance of $(p=0.001)$ in each case. The relationship was also significant $(p=0.001)$ between Willingness to Communicate with strangers and in public speaking and Attitude to learning English (10\% of variance), Motivational Intensity (10.3\% of variance), Desire to learn English (8.1\% of variance). Attitude towards learning English $\left(R^{2}=12.6\right)$, Motivational Intensity $\left(R^{2}=8.5\right)$ and Desire to learn English $\left(R^{2}=11.4 \%\right)$ had a significant ( $p=$ $0.001)$ relationship with Willingness to Communicate with strangers and interpersonal communication. She concluded that the higher the level in the factors, the more the students are willing to communicate in English. She also argued that communicative competence and regulating the Willingness to Communicate and actually to communicate are the ultimate goals of language learning. He recommended that more studies may help language teachers to improve their communication skills, teaching techniques and curriculum designs to provide better opportunities for language learners' communication willingness in English.

\section{Willingness to Communicate (WTC) in Malaysia}

Yousef et al. (2013) investigated Willingness to Communicate in a Private Malaysian university. The participants were all pre-service teachers from different intakes. The study hypothesized that: (i) "There is a positive relationship between language learning communication strategies and motivation to learn English; (ii) language learning communication strategies is positively related to communication competence; (iii) communication apprehension is negatively related to students' Willingness to Communicate in L2; (iv) selfperceived communication competence is positively related to students' Willingness to Communicate in second language; and (v) motivation is positively related to students' Willingness to Communicate in L2" (Yousef et al., 2013, p.4). A questionnaire was designed to collect demographic information and questions for measuring, motivation, language learning communication strategies and communication tendencies. The results showed that language learning communication strategies had a direct significant impact on students' Willingness to Communicate (WTC) in English. The study suggests that further research is recommended to investigate other variables such as personality traits, a person's desire to communicate with a specific person and Willingness to Communicate (WTC) in English. They also recommended to take into consideration Malaysia's multiculturalism and multilingualism in future research (Yousef et al., 2013).

Yazdi and Bakar (2014), studied Willingness to Communicate among four pairs of female Iranian and Malaysian students at a private university in Kuala Lumpur. He observed the dialogic behaviour by putting Iranians in two pairs with each other and Malaysians in two different pairs seeking homogeneity of their English proficiency, nationality, gender and academic background. They were asked to take part in fifteen writing tasks collaboratively. The researcher encouraged them to discuss the activities in English and not to use their mother tongue as much as they could. The researcher wrote observation notes while the students were engaged in collaborative writing, focusing on the participants' usage of their L1 and how they were willing to communicate with the researcher. He audiovideo recorded observation sessions to capture all missed points during his observation sessions which revealed that there were significant differences between Iranian and Malaysian dyads in the amount of using L1 and the times they sought help from the researcher during the collaborative sessions. Unlike Malaysian participants, switching to mother tongue was quite frequent among Iranians. Although participants showed an acceptable competency level in English, (dyad A, Iranian) strongly tended to switch to mother tongue. The researcher argued that the reason for code switching could be due to the students' difficulty to put meanings in English. Similarly, the second pair of Iranian dyads, tended to switch to mother tongue especially while discussing grammatical issues and to convey the meaning more accurately. They found it useless, boring and time consuming to talk about grammar in English. However, 
Malaysian participants seemed to have minimal switches to their mother tongue. The researcher reported that was because they were under the researcher's observation and tried to keep the observer (the researcher) in their discussions. This situation was different with Iranians as they were aware that the researcher can cope if they use their mother tongue. Noticeable level of shyness was observed regarding the Malaysian participants that may be due to the Asian culture of showing a great deal of respect and silence unless they were asked to talk by the person with authority (in this case the researcher).

\section{Methods}

\section{Research Setting}

The study took place in a private university located in Kota Damansara, Petaling Jaya, Selangor, Malaysia. This study was conducted in the Faculty of Education. The faculty offers five programs namely: (i) Teaching English as a Second Language, (ii) Early Childhood, (iii) Special Needs and (iv) Guidance and Counselling. (v) In addition to these programs there is a Special Diploma in Early Childhood. The medium of instruction is Mainly English but Bahasa Melayu is used for teaching some subjects. The faculty is following the Malaysian public policy of higher education in terms of degrees and regulations.

\section{Study Participants}

About 404 undergraduates studying at the Faculty of Education in Segi University, Selangor, Malaysia during the academic year of 2015. Students are mostly Malaysian from different ethnic groups aged between 18 and 22 years old. To make sure that different ethnic groups and different majors were represented in the study, stratified random sampling was used. All students were given the right to decline participating in the study.

\section{Instrumentation}

The data were collected through the Willingness to Communicate in English questionnaire. Background Information asked respondents to provide information like age, gender, ethnic group, academic course and the period they spent in the Faculty of Education.

\section{Willingness to Communicate (WTC) in English Questionnaire}

A twelve-item scale designed by (McCroskey, 1992) was used to measure students' Willingness to Communicate in English. The items measure some aspect of communication like group discussions, interpersonal conversations, public speaking and talking in meetings. The respondents have to choose the percentage of the Willingness to Communicate (WTC) between 0 (totally not willing to) and 100 (totally willing to). Scores were defined as the sum of the points that the respondent achieved based on the Willingness to Communicate (WTC) scale.

\section{Data Collection Procedures}

Data were collected from 230 randomly selected students through questionnaires. The researcher asked the lecturers who were in the classes to: (i) First, allow the researcher to give an idea about the study in classrooms and give detailed information about the research and assure confidentiality. (ii) Students who wanted to participate were given the set of questionnaires to fill in while those who refused to participate in the study stayed in their places. (iii) The researcher moved through the classrooms to make sure that students were not facing any difficulties with the questionnaires.

\section{Data Analysis}

Statistical Package for Social Sciences (SPSS) version 20.0 was used. A probability level of $p=0.05$ or less was set as the criterion for accepting or rejecting a null hypothesis that there will be no significant differences among the groups.

\section{Design Issues}

\section{Validity}

Confirmatory factor analysis was conducted to make sure the instrument used here is valid for the Malaysian context. Kaiser-Meyer-Olkin Measure of Sampling Adequacy (KMO) for Willingness to Communicate Questionnaire was (0.862) and $p$ value was $(p=<0.01)$.

\section{Reliability}

Each variable was checked for reliability using Cronbach alpha. Willingness to Communicate questionnaire was reliable to be used in this study ( $a=$ $0.873)$.

\section{Results}

\section{Willingness to Communicate in English}

The results of overall Willingness to Communicate in English showed that participants were moderate in their willingness to communicate in English $(M=54.25, S D=$ 19.617). Malaysian students' scores for Willingness to Communicate with friends $(M=62.08, S D=23.64)$ which is considered low compared to the norm developed by (McCroskey, 1992), ( $>99$ for high and $<71$ for low). 17 students said they were highly willing to communicate with friends in English (7.4\%) while 146 participants $(63.5 \%)$ showed low willingness to use English in communicating with friends. The remaining group of participants were $67(29.1 \%)$ were moderate in their 
Willingness to Communicate with friends in English. Looking at the scores for Willingness to Communicate with strangers, students were moderate $(M=46.41, S D=$ 23.30). The suggested norm by (Richmond and Roach, 1992) in communicating with strangers was (High $=>63$, Low $=<18)$. 66 students showed high Willingness to Communicate with strangers $(28.7 \%)$ while ten students said they never communicate with strangers (4.3\%). 22 students were lower than average in communicating with strangers and the remaining 131 $(57 \%)$ showed moderate level of Willingness to Communicate with strangers. The current study showed that Malaysian trainee teachers were moderate in the scores they gained when they were asked if they can speak in English among a large group of people in a public place $(M=56.26, S D=22.34)$. As shown in Table 1 , the norm for public speaking is $(>78,<22)$. They were lower than average in their intention to speak among a small group of people $(M=56.08, S D=$ 2.31). The norm set by (McCroskey, 1992) for native speaker was over 89 as highly willing to communicate and lower than 57 if not willing to communicate. The scores for interpersonal Willingness to Communicate were noticed to be twelve points lower than $(<64)$ the average set by McCroskey $(M=51.81, S D=22.18)$ compared to over 94 for native speakers' high Willingness to Communicate with an individual. While the lowest scores were found for Willingness to Communicate in a meeting $(M=50.13, S D=23.36)$ it was moderate based in the norm for native speakers ( $>80$ High, $<39$ Low).

\section{Willingness to Communicate in English and gender}

An independent-samples t-test was conducted to compare the scores of participants' overall Willingness to Communicate in English. There was a significant statistical difference between the scores of male students $(M=63.91, S D=20.41)$ and female students $(M=$ $53.57, S D=19.42) ; t(228)=-1.986, p=0.048)$.

\section{Willingness to Communicate in English and nationality}

The results of the independent sample $t$-test showed that there was no significant difference in the scores of participants based on the nationality in their WTC in English $(F(228)=0.221, p=0.825)$.

\section{Willingness to Communicate in English and ethnic group}

Indian participants were more willing to initiate communication in English $(M=74.67, S D=21.97)$ than Chinese students $(M=57.45, S D=0.87)$. There was also a significant difference in terms of communication with friends $(F(6,226)=6.975, p=0.001)$ as Indians were more willing to start a dialogue with friends $(M=74.67, S D=$ 21.97) than Malay students $(M=58.20, \mathrm{Sd}=19.47)$.

\section{Willingness to Communicate in English and course}

There was a significant statistical difference between the overall scores in Willingness to Communicate in English of those studying Teaching English as a Second Language (TESL) $(M=58.72, S D=17.54)$ and those studying Early Childhood Diploma (ECED) $(M=48.10$, $S D=19.34),(F(4,225)=3.959, p=0.005)$ which indicates that TESL students are more willing to start a conversation in English than those studying ECED. By looking at Communication in English with friends we can notice a significant differences $(F(4,225)=5.184, p$ $=0.001)$ between TESL $(M=70.11, S D=19.43)$ and ECED $(M=53.63, S D=22.83)$. There was also a significant statistical difference $(F(4,225)=3.245, p=$ $0.03)$ between the scores of TESL $(M=56.28, S D=$ $20.44)$ and ECED $(M=45.83, S D=22.36)$ in relation to Interpersonal Willingness to Communicate in English. Results also showed that TESL students were high in their intention to initiate a talk in English with a group of people $(M=61.23, S D=17.97)$ compared to those studying ECED $(M=48.63, S D=21.85)$. The relation was significant as $(F(4,225)=5.037, p=0.001)$. If we look at the result of the ANOVA test related to Willingness to Communicate in English in a meeting we find that there was a significant difference $(F(4,225)=$ $3.888, p=0.004)$ between the scores of TESL $(M=$ $55.65, S D=21.96)$ and the scores of ECED ( $M=42.56$, $S D=22.51)$. There were not statistically significant differences between study groups in their scores for strangers $(p=0.05)$, or public speaking $(0.485)$.

Table 1. Willingness to communicate

\begin{tabular}{|c|c|c|c|c|}
\hline & \multicolumn{2}{|c|}{ Current study } & \multicolumn{2}{|l|}{ Norm } \\
\hline & Mean & $\mathrm{SD}$ & High & Low \\
\hline Overall WTC & 54.2510 & 19.61700 & $>82$ & $<52$ \\
\hline Friend & 62.0870 & 23.64893 & $>99$ & $<71$ \\
\hline Stranger & 46.4174 & 23.30732 & $>63$ & $<18$ \\
\hline Public & 56.2826 & 22.34081 & $>78$ & $<22$ \\
\hline Group & 56.0870 & 21.31878 & $>89$ & $<57$ \\
\hline Interpersonal & 51.8116 & 22.18867 & $>94$ & $<64$ \\
\hline Meeting & 50.1304 & 23.36310 & $>80$ & $<39$ \\
\hline
\end{tabular}




\section{Willingness to Communicate in English and years spent in study}

There was no significant difference in the scores of participants in their overall Willingness to Communicate in English $(F(4,225)=2.23, p=0.067)$. On the other hand, the one-way ANOVA results showed that there were some significant differences between the scores of participants in some of the components of WTC. There was a statistically significant difference in the scores of Willingness to Communicate in English with strangers $(F(4,225)=2.723, p=0.03)$. There was a difference between students who spent one year at university $(M=$ $51.89, S D=25.32)$ and those who spent three years $(M=$ $37.76, S D=18.86),(p=0.023)$. Students who spent more than three years at university appeared to score more in their Willingness to Communicate with strangers $(M=51.46, S D=8.67)$ when compared to those who spent three years at university $(M=37.76, S D$ $=18.86),(p=0.048)$. The scores for public speaking showed that there was a significant difference between some of the groups from different years $(F(4,225)=$ $3.253, p=0.013$ ). Year three students had lower scores in Willingness to Communicate in English among a public $(M=46.43, S D=18.88, p=0.018)$ when compared with year one students $(M=59.35, S D=$ $20.35)$ and year two participants $(M=60.61, S D=23.25$, $p=0.008$ ). We can conclude that year three students are the least willing to communicate in English with strangers and in public speaking context.

\section{Discussion}

Table 2 shows the results of Willingness to Communicate in English in two Asian countries, the current study, compared to the results of WTC in the USA. The comparison revealed that Malaysian university students were the highest in their overall Willingness to Communicate compared to the two Asian studies but lower than the results of the American study. Communication with friends was almost the same between the current study and the study conducted in Hong Kong, while the lowest were the results of the Korean study. Still the American study showed higher scores. Interestingly, Malaysian students were the highest in their scores for Willingness to Communicate with strangers among the four studies. The current study also revealed that Malaysian participants were the highest in their scores for public speaking followed by USA, Hong Kong, then Korea. For group discussion, the results of the current study were preceded by the American and followed by the two Asian studies. Korean students came next after the American, followed by Malaysian participants in interpersonal Willingness to Communicate while those from Hong Kong scored the lowest. If we look at the scores of meeting, we notice that Malaysian students scored higher than the students from the two other studies from Asia and came second compared with Americans. Generally, the current study showed that Malaysian university students were the most willing to communicate among the three Asian studies and were better than the American study in their scores for Willingness to Communicate with strangers.

The results of WTC in English in terms of gender showed that generally male students are more willing to communicate in English than female students $(p=$ 0.048). A study on gender differences in WTC found that there was no difference between male and female participants (Donovan and MacIntyre, 2004). The researcher reported the exact $p$ value to show that the significance of that difference is not very strong. In a different context Iranian female learners were found outperforming Willingness to Communicate (Alavinia and Alikhani, 2014). The researcher also found it useful to note that the sample in the current study was not balanced $($ Male $=15$, Female $=215)$ reflection the studied population $($ Male $=26$, Female $=378)$.

The results of the current study showed that there were no significant differences in term of nationality among Malaysian trainee teachers $(p=0.825)$ while there were significant differences based on the ethnic group in overall WTC $(p=0.037)$. Indian participants showed the highest Willingness to Communicate with friends when compared with Chinese $(p=0.0001)$ and Malay $(p=0.001)$. The findings here were supported by an ethnographic study showing that Indians were the best in English language in terms of speaking, reading and writing (Azman, 1999). In the current study, one-way ANOVA test on WTC showed that there were significant differences among participants in terms of their course in the Faculty of Education $(p=0.004)$.

Table 2. Results of some studies on willingness to communicate

\begin{tabular}{lllll}
\hline Measure & USA 1992 & Hong Kong 1996 & Korea 2011 & Current Study 2016 \\
\hline Friend & 84.7 & 61.3 & 55.1 & 62.1 \\
Stranger & 38.5 & 32.0 & 40.7 & 46.4 \\
Public & 54.2 & 45.9 & 41.2 & 56.3 \\
Group & 70.8 & 48.3 & 47.1 & 56.1 \\
Interpersonal & 76.2 & 42.2 & 61.7 & 51.8 \\
Meeting & 59.7 & 42.2 & 46.8 & 50.1 \\
Total WTC & 65.6 & 44.7 & 49.2 & 54.3 \\
\hline
\end{tabular}


The differences were noticed between TESL and ECED students in their overall WTC $(p=0.005)$, WTC with friends $(p=0.0001)$, interpersonal $(p=0.30)$, group discussion $(p=0.001)$ and WTC in meetings $(p=0.004)$. That supports the primary observations of the researcher as ECED students showed difficulty to understand the questionnaire and asked for help from the researcher and sometimes asked their friends to translate into their mother tongue (Malay and Chinese). The researcher discussed with the lectures who reported that ECED students were facing problems with their English language and tend to use their mother tongue in communication. There were no significant differences among participants in terms of the number of years they had spent in their tertiary study regarding overall Willingness to Communicate $(p=0.067)$. It was noticed that the scores of students who spent three years at the faculty of education were the lowest in WTC with strangers compared with those who spent one year ( $p=$ $0.23)$ and those who spent more than three years $(p=$ 0.48 ). those who spent three years of study were also the lowest WTC in public speaking compared with those who spent one year $(p=0.018)$ and those who spent two years $(p=0.08)$. Jung (2011) reported that Asian students tend to be less willing to communicate to avoid being looked down at them because they commit mistakes in grammar or are not able to express themselves. Chinese students were found unwilling to communicate in English in front of a public as part of their culture and traditions shaping the relation between students and teachers (Wen and Clément, 2003).

\section{Conclusions and Recommendation}

This study investigated Malaysian trainee teachers' Willingness to Communicate in English They preferred to initiate communication in English with friends rather than acquaintances or strangers. Male participants were significantly different in their overall willingness to communicate, were more willing to communicate with friends, more willing to communicate in English in a meeting. Indian students seemed to be more willing to communicate in English with friends more than Chinese and Malay participants. English major students were the most willing to communicate in English with friends, in groups, during a meeting and individually. Students from different years were moderately willing to communicate with strangers and to address a public compared with those who spent three years of study who were the most unwilling to communicate with strangers and did not prefer to go for public speaking.

The results of the current study highly recommend that greater concern to be given to cultural and individual factors that affect WTC in English. Lecturers should understand the diversity in the factors affecting
Willingness to Communicate in English. The researcher in the present study would like to place the following recommendations: First, screening trainee teachers' cognitive abilities, attitudes about self and university, as well as their language skills when they first come to the faculty of education is the key to understanding their abilities and limitations. Second, providing more opportunities for student to communicate in English can be achieved by changing classroom environment, teaching techniques and especially grouping techniques to avoid putting students from the same ethnic group in the same group. Third, encouraging trainee teachers to participate in different activities outside the classrooms. English language clubs, journeys to native speaking countries, debates, drama, songs and free writing competitions can help them learn more away from the stress caused be curriculum based activities linked to assessment and grades. Fourth, it is suggested that a centre to be started for academic writing to provide training, checking, as well as advice away from official classes and marking. Fifth, stronger relationships with parents can help better understand any changes that may take place away from university. Sixth, it is suggested that WTC needs to be redefined in second language context. The current measurement and the norm based on it were designed in first language context and looked at WTC as a trait-like. The results of the current study showed that participants mentioned other factors that affect their decision to communicate with a particular person in one situation while they are not willing to do so with the same person if the time is different or the feelings has changed towards that person. Seventh, it is a must to link the choice of applicants to the faculty of education to be among the best performers in the national assessment tools like (SPM) to ensure the quality of future teachers. Eighth, it is suggested to make use of new features in Learning Management Systems (LMS) that allow lecturers to start a topic and invites students to discuss by writing, sending voice messages and short videos for themselves.

\section{Acknowledgment}

I would like to express my sincere gratitude to Prof. Dr Mogana Dhamotharan for her intellectual and emotional support. Furthermore, my warmest thanks go to Ms Lydia Foong, Head of the Faculty of Education, SEGi University. I would also like to thank Dr Palanisamy Veloo and Dr Shaheen Mansori who provided support and assistance to me during my study by sharing their statistical knowledge and insights. I also greatly appreciate the assistance from the faculty and students at SEGi University. It would have been difficult to conduct this study without their willingness and precious help throughout the data collection process. Finally, my greatest sincere thanks go to my family for 
their love and unconditional support during my academic career. I would like to thank my beloved wife Reda and my son Mohamed, uncles and aunts, sisters and brother for their precious support. Without their support, I would never be able to reach where I am today.

\section{Author's Contributions}

Ahmed Fahim: Designed the research plan, organized the study, collected the data, carried out the analysis and interpretation of data, drafted the article and gave the final approval of the version to be submitted and the revised version.

Mogana Dhamotharan: Supervised the study as a whole. In addition to that, she revised it critically for grammatical and spelling mistakes.

\section{References}

Alavinia, P. and M.A. Alikhani, 2014. Willingness to communicate reappraised in the light of emotional intelligence and gender differences. Proc. Soc. Behav. Sci., 98: 143-152.

DOI: $10.1016 /$ j.sbspro.2014.03.400

Azman, H., 1999. Language in rural Malaysia.

Blueprint, M.E., 2013. Malaysia education blueprint.

Burgoon, J.K., 1976. Unwillingness to communicate scale. Commun. Monographs, 43: 60-69.

DOI: $10.1080 / 03637757609375916$

Cao, Y., 2011. Investigating situational willingness to communicate within second language classrooms from an ecological perspective. System, 39: 468-479.

Crozier, W.R., 1982. Explanations of social shyness. Curr. Psychol. Rev., 2: 47-59. DOI: $10.1007 / \mathrm{BF} 02684454$

Donovan, L.A. and P.D. MacIntyre, 2004. Age and sex differences in willingness to communicate, communication apprehension and self-perceived competence. Commun. Res. Rep., 21: 420-427. DOI: $10.1080 / 08824090409360006$

Fern, N.P. and Y.K. Jiar, 2012. Preschool teachers' beliefs and practices on early literacy instruction. Seminar Kebangsaan Majlis Dekan Pendidikan IPTA.

Gill, S.K., 2005. Language policy in Malaysia: Reversing direction. Lang. Policy, 4: 241-260. DOI: 10.1007/s10993-005-7859-9

Ida Fatimawati, A.B., 2012. A Study on the relationship between Malaysian Learners' Self-concept in Academic Writing and their Engagement.

Jung, M.A., 2011. Korean EFL university students' willingness to communicate in English. Indiana University.

Lahuerta, A.C., 2014. Factors affecting willingness to communicate in a Spanish university context. Int. J. English Stud., 14: 39-55. DOI: 10.6018/j.193611
LOM, 2006. Private higher educational institutions act.

Mahady. (n.d.). Corpus Linguistics Based Error Analysis of First Year Universiti. Atlantic.

McCroskey, J.C. and J.E. Baer, 1985. Willingness to communicate: The construct and its measurement. Proceedings of the Annual Meeting of the Speech Communication Association, Nov. 7-10, Denver, CO.

McCroskey, J.C., 1992. Reliability and validity of the willingness to communicate scale. Commun. Q., 40: 16-25. DOI: 10.1080/01463379209369817

McCroskey, J.C., 2006. The role of culture in a communibiological approach to communication. Human Commun., 9: 31-35.

Mortensen, C.D., P.H. Arnston and M. Lustig, 1977. The measurement of verbal predispositions: Scale development and application. Human Commun. Res., 3: 250-257. DOI: $10.1111 / \mathrm{j} .1468-2958.1977 . t b 00513 . \mathrm{x}$

Priest, R.F. and J. Sawyer, 1967. Proximity and peership: Bases of balance in interpersonal attraction. Am. J. Sociol., 72: 633-649. DOI: 10.1086/224400

Richmond, V.P. and K.D. Roach, 1992. Willingness to communicate and employee success in U.S. organizations. J. Applied Commun. Res., 20: 95-115. DOI: 10.1080/00909889209365321

MGBSLN, 2015. Room for improvement | New Straits Times | Malaysia General Business Sports and Lifestyle News.

Wen, W.P. and R. Clément, 2003. A Chinese conceptualisation of willingness to communicate in ESL. Lang. Culture Curriculum, 16: 18-38. DOI: $10.1080 / 07908310308666654$

Yazdi, S.Y. and K.A. Bakar, 2014. An observation account from EFL/ESL Dyads: Code-switching and willingness to communicate. Int. J. Educ. Literacy Stud., 2: 1-4. DOI: 10.7575/aiac.ijels.v.2n.1p.82

Yousef, R., H. Jamil and N. Razak, 2013. Willingness to communicate in English: A study of Malaysian preservice English teachers. English Lang. Teach., 6: 205-216. DOI: 10.5539/elt.v6n9p205 